Discussion Paper No. 953

\title{
TECHNOLOGY TRANSFER \\ IN THE MARKET \\ WITH HETEROGENEOUS CONSUMERS
}

\author{
Shohei Yoshida \\ Cong Pan
}

December 2015

The Institute of Social and Economic Research

Osaka University

6-1 Mihogaoka, Ibaraki, Osaka 567-0047, Japan 


\title{
Technology Transfer in the Market with Heterogeneous Consumers*
}

\author{
Shohei Yoshida ${ }^{\dagger}$ Cong Pan \\ Graduate School of Economics, Osaka University
}

December 24, 2015

\begin{abstract}
The paper explains why some firms transfer their technology to competitors without direct compensation. We consider a Hotelling market where duopolists sell products with different qualities. This market consists of heterogeneous consumers, comprising two groups in terms of their valuations of product quality. We show that when consumers' preferences for product quality are sufficiently heterogeneous, a high-quality firm benefits from qualityenhancing technology transfer without payment. Furthermore, we extend the model to a circular city with four firms and show that a firm can benefit from a technology transfer to direct competitors rather than to an indirect competitor.
\end{abstract}

Keywords: Technology transfer, Competitor collaboration, Consumer heterogeneity JEL Classification Numbers: L24, L41, M21

\footnotetext{
*We are especially grateful to Noriaki Matsushima for his valuable advice. We would also like to thank Keisuke Hattori, Akio Kawasaki, Tomomichi Mizuno, Yusuke Zennyo, the conference participants at the Japanese Economic Association (Niigata University), and the seminar participants at Kyoto University and Osaka University for their very useful comments. The second and corresponding author acknowledges the financial support from the Japan Society for the Promotion of Science (Pan, 15J05223). All remaining errors are our own.

${ }^{\dagger}$ Address: Graduate School of Economics, Osaka University, 1-7 Machikaneyama, Toyonaka, Osaka 5600043, Japan. E-mail: pge031ys@student.econ.osaka-u.ac.jp

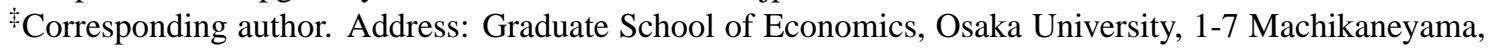
Toyonaka, Osaka 560-0043, Japan. E-mail: pge042pc@student.econ.osaka-u.ac.jp
} 


\section{Introduction}

We often observe that firms form an alliance with their competitors. It has been widely recognized in the management literature that one of the most fundamental motivations of strategic alliances is the transfer of technology or knowledge between partner firms. ${ }^{1}$ Although one may think of licensing as a way to conduct a technology transfer, the management literature shows that it is not always applicable because tacit technology is unverifiable and difficult to be licensed. ${ }^{2}$ Even for some explicit technologies, licensing is not applied, because the mechanism is very complex and costly. ${ }^{3}$ To provide alliance partners access to these implicit or sophisticated technologies, an advanced firm may even conduct a transfer without receiving direct compensation. ${ }^{4}$ This might be surprising from a common sense perspective since non-compensated sharing of one's patentable technology means a loss in advantage that should be avoided even at a cost. However, some empirical works suggest that free technology transfer exists and is not a rare phenomenon in various industries. ${ }^{5}$

Our research questions are as follows: why some firms may transfer their technology to competitors without any payments, and how consumers' characteristics affect the incentive for technology transfers. To this end, we first consider a Hotelling duopoly market wherein firms have different technologies in terms of both quality and efficiency. Each firm monopolizes a group of consumers with strong brand loyalty while competing for other consumers between them. Thus, this market consists of a "duopoly submarket" and two "monopoly submarkets."

\footnotetext{
${ }^{1}$ Gomes-Casseres et al. (2006), for example, find that knowledge flows between alliance partners are greater than these between pairs of non-allied firms. See also Hamel (1991) and Mowery et al. (1996).

${ }^{2}$ For further details of contractual difficulties in transferring tacit knowledge, see Mowery (1983, p. 354) and Ghosh and Morita (2012).

${ }^{3}$ Harhoff et al. (2003) summarize many empirical works and cases wherein licensing is not chosen for transferring explicit technology in some industries.

${ }^{4}$ Other ways for carrying out these types of technology transfer are by organizational combinations such as joint production or partial equity ownership. A joint venture is a good example (Kogut, 1988). Creane and Konishi (2009) show numerous cases of joint production with technology transfer in the metallurgical, automobile, and packaging industries.

${ }^{5}$ Morita et al. (2010) investigate collaborations among firms and observe 88 cases wherein a firm transfers its technology without direct compensation. Notably, 59\% of the technology transfers occur between firms without partial equity ownership, which shows that free technology transfer plays an important role.

${ }^{6}$ Take the videogame software market as an example, where consumers have already bought gaming hard-
} 
Two key assumptions concerning heterogeneity in consumers' preferences are made. First, we assume that consumers can be segmented into groups, and each one shows a specific brand preference. Second, we assume that these groups are heterogeneous in consumer's valuation of product quality. Kamakura and Russell (1993) empirically show the rationality of our assumptions. Regarding the first assumption, data analysis on the powder laundry detergent category in the US shows that some consumers have a pronounced preference for one brand and therefore develop strong brand loyalty, while others buy from several brands. These consumers are then segmented into different groups according to their heterogeneous brand preferences. For our second assumption, Kamakura and Russell (1993) show that consumer's valuation of the same features of a brand can be heterogeneous among these groups. ${ }^{7}$

We show the following results. First, when consumers' preferences for the product quality are sufficiently heterogeneous, a technology advantaged firm benefits from transferring its quality-enhancing technology to a technology inferior firm without direct compensation. Second, a firm with low-cost technology cannot benefit from a cost-reducing technology transfer. Furthermore, we extend the model to a circular city with four firms and four consumer groups and show that a firm can benefit from a quality-enhancing technology transfer to direct competitors rather than to an indirect competitor.

The logic behind our first result is as follows. When the consumers in monopoly submarket of the firm with inferior technology (the technology recipient) valuate the quality enhancement more than those in the duopoly submarket, the demand for this firm increases more in the monopoly submarket than that in the duopoly submarket. This is clearly harmful to the firm with superior technology since its market share declines in the duopoly submarket. However, the technology recipient charges a higher price due to increased demand, which benefits the technology advantaged firm by decreasing its rival's demand in the duopoly sub-

ware. PlayStation or Xbox, for instance, belong to the monopoly submarket, and new consumers belong to the duopoly submarket.

${ }^{7}$ Needless to say, economists have also theoretically focused on the heterogeneity of consumer preference. To see more theoretical studies with respect to how consumers heterogeneity affects firms' behaviors, refer to Shaked and Sutton (1982) and Ishibashi and Matsushima (2009). 
market. In the duopoly submarket, the latter (strategic) effect from a price increase can dominate the former (direct) effect from quality enhancement; hence, the technology recipient loses share in the duopoly submarket under some conditions. Thus, the technology advantaged firm benefits from a technology transfer by obtaining more demand in the duopoly submarket.

Our second result shows that the effect on a firms' profit is opposite whether qualityenhancing or cost-reducing technology is transferred. The intuition is straightforward. In our first result, a technology transfer makes a rival to charge a higher price. If the technology advantaged firm instead transfers its technology which makes its rival more efficient, the technology recipient has an incentive to lower its price, which causes the technology advantaged firm to lose market share in the duopoly submarket.

In contrast to the original model, the extended model allows us to analyze the following question: whom should a technology advantaged firm transfer its quality-enhancing technology to? The intuition behind our third result parallels the first. In this model, every two firms compete for a duopoly submarket, wherein each consumer group has a different preference about product quality. When the firm with superior technology transfers its qualityenhancing technology to the direct competitor, the direct competitor expands its share, which is negative for the technology advantaged firm. However, following our first result, the technology advantaged firm may obtain a higher demand from the higher price charged by the technology recipient, which can surpass the former negative effect. In contrast, the technology transfer to an indirect competitor increases the technology recipient's demand and price, forcing direct competitors to adapt by undercutting prices. This always diminishes the technology advantaged firm's profit.

Our study also has managerial implications for imitation deterrence and industry advertising strategies. First, the extent of tolerance toward rival's imitation activity varies among product properties. Our findings give a possible marketing strategy: a rival's imitation of product quality may be permitted or even encouraged. Second, from conventional wisdom, a firm should expect its advertisement to enhance consumers' willingness to pay only for its 
own product, rather than a rival's in the same industry. Our results imply that this viewpoint can have an opposite result: it can be profitable for a firm's advertisement to help propagate a rival' products.

Several papers theoretically discuss the technology transfer among competitors. ${ }^{8}$ Creane and Konishi (2009) discuss an asymmetric oligopoly with free entry and exit. An efficient incumbent firm transfers its cost-reducing technology to another less efficient one. In doing so, profits of alliance partners are enhanced by forcing exit. Matsushima and Ogawa (2012) discuss a location problem for multiproduct firms. Firms choose whether to disclose cost-reducing technology. Only when the entrants are in the different location with the incumbent firm can they use their know-how. The incumbent firm benefits from the transfer by driving entrants to a different location. Our study differs from the above two studies as we do not consider free entry or exit. Yoshida (2015) develops a multiproduct Cournot model with a vertical structure and shows that an efficient firm may have an incentive for a technology transfer without any payment to its competitor. Matsushima and Zhao (2015) discuss a bilateral duopoly market wherein downstream firms have outside options when Nash bargaining breaks down, and show that each upstream firm may voluntarily generate technological spillover to its rival. Rather than considering a quantity competition model, we employ a price competition model without vertical relationship. ${ }^{9}$

This paper also relates to the literature that examines effects of consumer heterogeneity on market outcomes. We first became inspired by Desai (2001), whose market structure is similar to ours: consumers are divided into two groups based on their valuations of each firm's products, either high or low. That is, consumers are heterogeneous in terms of quality valuations as well as taste preferences. ${ }^{10}$ We employ a modified version wherein each firm

\footnotetext{
${ }^{8}$ The literature related to technology transfer without payment is sparse because most studies focus on how to provide license to competitors or how to reduce counterfeiting under weak intellectual property rights (e.g., Qian, 2014).

${ }^{9}$ Ghosh and Morita (2012) consider the technology transfer between firms with a partial equity ownership. In their model, partial equity ownership is a necessary prerequisite for technology transfer. Milliou and Petrakis (2012) show that a vertically integrated firm can choose to fully disclose its knowledge to its downstream rival. This technology transfer intensifies downstream competition but expands downstream market size, which increases the wholesale revenue of the vertically integrated firm.

${ }^{10}$ In addition, Tyagi (2004), Ellison (2005) and Shi et al. (2013) assume both vertical and horizontal heterogeneity. Ellison (2005) considers two consumer types for quality valuations, whereas Tyagi (2004) and Shi et
} 
monopolizes a high-valuation consumer group (or consumers with strong brand loyalty). Chen and Riordan (2007) discuss a similar model, which involves consumer heterogeneity. ${ }^{11}$ Their model has three relevant categories of consumers: (i) consumers whose first and second preferred brands are available; (ii) consumers whose first preferred brand is available, whereas the second preferred one is not; (iii) consumers whose second preferred brand is available, whereas the first preferred one is not. Consumers in the duopoly (monopoly) submarket in our model may correspond to those in category (i) ((ii) or (iii)). Varian (1980) also considers how the existence of heterogeneous consumer groups affects firms' pricing strategies. In this model, heterogeneity comes from each consumer's different information. We can also interpret that consumers in a monopoly submarket lack information about one of these two firms. Therefore, we can apply our results to various market structures.

The rest of the paper is organized as follows: Section 2 sets up our model, Section 3 derives an equilibrium and analyzes the incentive for a technology transfer, Section 4 extends our model and shows further results, and Section 5 offers some concluding remarks.

\section{A Simple Model}

Consider a linear city along the interval $[0, \infty)$, wherein consumers are uniformly distributed on $[0,1]$ with mass 1 , while on $(1, \infty)$ with mass $M .{ }^{12}$ Firm $i(i=0,1)$ is located at $i$ and selling a product of quality $q_{i}$. Let $p_{i}$ denote the price of products of firm $i$.

[Figure 1 about here]

There are two groups of consumers, $D$ and $M$. Consumers $D$ are in a duopoly market supplied by both (i.e., duopoly submarket). Consumers $M$ are in a monopoly market supplied al. (2013) consider continuous type.

${ }^{11}$ Reggiani (2014) extends Chen and Riordan's (2007) basic spokes structure to a spatial model wherein each firm decides its position on the spoke assigned by nature and discriminates consumers in price based on their respective spokes.

${ }^{12}$ For simplicity, we assume that consumers in one of these two ranges are distributed infinitely. This assumption can be relaxed. Additionally, we assume asymmetric densities of the two submarkets. The derived propositions about consumer heterogeneity are given, including terms of the relative size of these two submarkets. If we instead assume symmetric densities for these two ranges, and asymmetry in consumers' transportation cost as in Desai (2001) and Pazgal et al. (2013), the conditions for our propositions can also be modified in terms of heterogeneity in consumers' tastes. 
by only firm 1 (i.e., monopoly submarket). For simplicity, we analyze this asymmetric model wherein only firm 1 has a monopoly submarket. We obtain qualitatively similar results if we assume that each firm has a monopoly submarket. Furthermore, as shown in Section 4, while different submarkets are essential for our results, the monopoly submarket is not necessarily needed.

Consumers buy up to one unit from one of the firms. Each group of consumers has different preferences over product quality, ${ }^{13}$ which are represented by the differentiable functions $v_{D}(q)$ and $v_{M}(q) .{ }^{14}$ It is natural that consumers' willingness to pay should increase with product quality. However, $v(q)$ here need not be strictly increasing in $q .{ }^{15}$ The utility of the consumer located at $x \in[0,1]$ is given by,

$$
U_{D}(x)= \begin{cases}k+v_{D}\left(q_{0}\right)-p_{0}-t x & \text { if she buys from firm } 0 \\ k+v_{D}\left(q_{1}\right)-p_{1}-t(1-x) & \text { if she buys from firm } 1 \\ 0 & \text { if she does not buy, }\end{cases}
$$

where $k$ is a sufficiently large positive constant, but not too large to ensure interior solutions for mathematical simplicity. The parameter $t$, the exogenous parameter of transport cost incurred by the consumer, measures the substitutability between any given pair of products. This formulation can be justified as follows: the product comprises several characteristics and consumers are heterogeneous in evaluating one of these characteristics. It is along that characteristic each firm differentiates its product. As for the other characteristics, consumers are homogeneous and $k$ is their common valuation (Belleflamme and Peitz, 2010, p. 224).

The utility of the consumer located at $y \in(1, \infty)$ is given by

$$
U_{M}(y)= \begin{cases}k+v_{M}\left(q_{1}\right)-p_{1}-t(y-1) & \text { if she buys from firm } 1 \\ 0 & \text { if she does not buy. }\end{cases}
$$

Let $\hat{x}_{01}\left(p_{0}, p_{1}\right)$ be the consumer who is indifferent between buying from firm 0 and firm 1 and $\hat{y}_{1}\left(p_{0}, p_{1}\right)$ be the consumer who is indifferent between buying from firm 1 and buying

\footnotetext{
${ }^{13}$ In Tirole (1988, pp. 143-144), the consumer taste parameter can be denoted by the inverse of the "marginal utility of income." Thus, consumers with different incomes have varying willingness to pay.

${ }^{14}$ We employ the model with consumer heterogeneity in terms of quality valuation. We would obtain essentially similar results with heterogeneous consumer groups in terms of price elasticity, as in Ellison (2005).

${ }^{15}$ For example, young people expect smart phones with many functions. However, this is not the case for older individuals.
} 
nothing. The values of $\hat{x}_{01}$ and $\hat{y}_{1}$ are given as follows:

$$
\hat{x}_{01}=\frac{1}{2}+\frac{v_{D}\left(q_{0}\right)-v_{D}\left(q_{1}\right)+p_{1}-p_{0}}{2 t},
$$

and

$$
\hat{y}_{1}=1+\frac{k+v_{M}\left(q_{1}\right)-p_{1}}{t} .
$$

Thus, the demand facing firm $0, D_{0}$, and that facing firm $1, D_{1}$, are given by

$$
D_{0}=\frac{1}{2}+\frac{v_{D}\left(q_{0}\right)-v_{D}\left(q_{1}\right)+p_{1}-p_{0}}{2 t}
$$

and

$$
D_{1}=\left(\frac{1}{2}+\frac{v_{D}\left(q_{1}\right)-v_{D}\left(q_{0}\right)+p_{0}-p_{1}}{2 t}\right)+M\left(\frac{k+v_{M}\left(q_{1}\right)-p_{1}}{t}\right) .
$$

Assume that the constant marginal cost of firm $i$ is $c_{i}$ and that $c_{0}$ is normalized to 0 . Thus, firm 0 has both high-quality and low-cost technology, which implies that the technologies are correlated. However, this assumption is not crucial for our results. ${ }^{16}$ The profits of firm $i$ are

$$
\pi_{i}=\left(p_{i}-c_{i}\right) D_{i}
$$

Hereafter, we restrict our attention to interior solutions. In our model, firm 1 gets profit from both the duopoly and monopoly submarkets. It is possible that firm 1 still benefits from abandoning the duopoly submarket, specializing in supplying only the monopoly submarket. For example, when $k$ is very large, firm 1 can benefit by setting such a price that consumers in the duopoly submarket do not buy from firm 1 at all. To eliminate this case, we implicitly assume that $k$ is not too large. As we discuss in the next section, the conditions for our results hold when an interior solution exists.

In this setting, firms engage in one-shot price competition. Note that decision making related to a technology transfer is not included in the game. We analyze whether firms have an incentive for a technology transfer by comparative statics.

\footnotetext{
${ }^{16}$ We do not have to explicitly assume which firm is a high-quality firm. Since a natural presumption is that a high-quality firm can transfer its technology to a low-quality one, it is natural to assume that $q_{0}>q_{1}$. If the low-quality firm can transfer its technology to a high-quality one, we do not need this assumption.
} 


\section{Analysis}

In this section, we go through firms' optimization problems. Since the model is standard, we briefly sketch the outline of the analysis. Each firm chooses its price $p_{i}$ so as to maximize its own profit. After few line computations, we have the reaction functions,

$$
\begin{aligned}
& R_{0}\left(p_{1}\right)=\frac{v_{D}\left(q_{0}\right)-v_{D}\left(q_{1}\right)+t+p_{1}}{2} \\
& R_{1}\left(p_{0}\right)=\frac{2 M\left[k+v_{M}\left(q_{1}\right)+c_{1}\right]+v_{D}\left(q_{1}\right)-v_{D}\left(q_{0}\right)+t+c_{1}+p_{0}}{2(1+M)} .
\end{aligned}
$$

Note that a direct effect of an increase in $q_{1}$ shifts firm 0's reaction function downwards and shifts firm 1's reaction function upwards. The valuations for product quality $v_{M}$ and $v_{D}$ strongly relate to the effect on the firm 1's reaction function.

Assuming that an interior solution exists, the equilibrium prices are

$$
\begin{aligned}
& p_{0}^{*}=\frac{(1+4 M)\left[v_{D}\left(q_{0}\right)-v_{D}\left(q_{1}\right)\right]+2 M\left[k+v_{M}\left(q_{1}\right)\right]+(3+4 M) t+(1+2 M) c_{1}}{3+8 M}, \\
& p_{1}^{*}=\frac{v_{D}\left(q_{1}\right)-v_{D}\left(q_{0}\right)+4 M\left[k+v_{M}\left(q_{1}\right)\right]+3 t+2(1+2 M) c_{1}}{3+8 M} .
\end{aligned}
$$

Equations (10) and (11) show that an increase in $v_{M}\left(q_{1}\right)$ motivates firm 1 to raise its price to further exploit consumers in the monopoly submarket. firm 0 can benefit from this effect due to strategic complementarity.

The resulting firms' profits are

$$
\begin{aligned}
& \pi_{0}^{*}=\frac{\left\{(1+4 M)\left[v_{D}\left(q_{0}\right)-v_{D}\left(q_{1}\right)\right]+2 M\left[k+v_{M}\left(q_{1}\right)\right]+(3+4 M) t+(1+2 M) c_{1}\right\}^{2}}{2 t(3+8 M)^{2}} \\
& \pi_{1}^{*}=\frac{(1+2 M)\left\{4 M\left[k+v_{M}\left(q_{1}\right)\right]-v_{D}\left(q_{0}\right)+v_{D}\left(q_{1}\right)+3 t-(1+4 M) c_{1}\right\}^{2}}{2 t(3+8 M)^{2}}
\end{aligned}
$$

We now turn to the central issue, namely the incentive for the technology transfer, which enhances the quality of a rival firm without direct compensation. Consider that firm 0 can transfer its quality-enhancing technology on product quality to firm 1 , and that the transfer maintains the efficiency level of firm 1 . The following result is obtained. 
Proposition 1 Firm 0 may have an incentive to transfer its quality-enhancing technology without any payment. Formally,

$$
\frac{d \pi_{0}^{*}}{d q_{1}}>0 \Leftrightarrow \frac{v_{D}^{\prime}\left(q_{1}\right)}{v_{M}^{\prime}\left(q_{1}\right)}<\frac{2 M}{1+4 M} .
$$

The intuition behind Proposition 1 is that a technology transfer has both direct and indirect effects on a firm's profit, and these effects work in opposite directions. A technology transfer enhances the quality of a rival firm, which directly reduces the demand for firm 0 (see Equation (5)). Note that a technology transfer has a different impact on quality valuation for each type of consumer. Under the proposition's condition, consumers in a monopoly submarket evaluate quality enhancement more than those do in the duopoly submarket. On the other hand, firm 1 increases its price to adjust to the increased demand due to the direct effect. For firm 1's demand from the duopoly submarket, the direct effect from quality enhancement can be dominated by the indirect effect from the price increase; hence, the overall effect of the transfer can reduce firm 1's demand from the duopoly submarket. Thus, both firm 0 and firm 1 benefit from a technology transfer by obtaining more demand.

Note that the left-hand side of the condition for Proposition 1 depends only on the derivatives of $v_{M}$ and $v_{D}$. Thus, we can find a certain parameter set, that satisfies both the interior solution condition and that of Proposition 1. This argument can be applied to the other propositions in this paper as well. In addition, it is noteworthy that the condition in Proposition 1 would relax when better technology makes firm 1 enjoy a quality enhancement while undertaking higher cost, because rising cost further drives up firm 1's price.

Now we turn to the next question: does a firm have an incentive to transfer its costreducing technology to its competitor?

Proposition 2 Firm 0 has no incentive to transfer its cost-reducing technology without any payment. Formally, $d \pi_{0}^{*} / d c_{1}>0$.

The intuition behind the proposition is as follows. Transfers of quality-enhancing technology and cost-reducing technology have absolutely opposite effects on firm 1's pricing strategy. The former increases firm 1's price while the latter decreases it. When firm 1 low- 
ers its marginal cost, firm 0 has to undercut its price; therefore, its profit decreases. Hence, firm 0 does not transfer cost-reducing technology to its rival.

\section{Extension of the Model}

Consider a model extended to a circular city model with four firms, as in a la Vickrey (1964) and Salop (1979). ${ }^{17}$ Firm $i \in\{0,1,2,3\}$ is located at $i / 4$ and is selling a product of quality $q_{i}$. Assuming that each firm produces at no cost, we only need discuss transfers of qualityenhancing technology. We also assume that a unit mass of consumers is uniformly distributed on a circle of circumference 1 and that consumers are categorized into four groups depending on their locations. We now call consumers between firm $i$ and $i+1$, type $i i+1$. Their preferences over a product's quality are represented by function $v_{i+1}(q)$. The structure of the extended model is depicted in Figure 2.

[Figure 2 about here]

The utility of the consumer located at $x \in[i / 4,(i+1) / 4)$ is

$$
U_{i+1}(x)= \begin{cases}k+v_{i+1}\left(q_{i}\right)-p_{i}-t d\left(x, \frac{i}{4}\right) & \text { if she buys from firm } i \\ k+v_{i+1}\left(q_{i+1}\right)-p_{i+1}-t d\left(x, \frac{i+1}{4}\right) & \text { if she buys from firm } i+1, \\ 0 & \text { if she does not buy, }\end{cases}
$$

where $d(x, i / 4)$ is the distance between consumer $x$ and firm $i$ on the circle. When $i+1=4$, we replace 4 with $0 .{ }^{18}$

Let $\hat{x}_{i j}\left(p_{i}, p_{j}\right)$ be the consumer whose utility does not change, regardless of which firm is chosen. These are

$\hat{x}_{01}\left(p_{0}, p_{1}\right)=\frac{1}{8}+\frac{v_{01}\left(q_{0}\right)-v_{01}\left(q_{1}\right)+p_{1}-p_{0}}{2 t}, \hat{x}_{12}\left(p_{1}, p_{2}\right)=\frac{3}{8}+\frac{v_{12}\left(q_{1}\right)-v_{12}\left(q_{2}\right)+p_{2}-p_{1}}{2 t}$,

\footnotetext{
${ }^{17}$ We can easily extend the model to more than four firms. However, analysis of a market with four firms is important because each firm has both direct and indirect competitors.

${ }^{18}$ Consumers' preferences are similar to those in Chen and Riordan (2007), wherein each consumer only cares about two possible brands, in contrast to Salop (1979). Although we can employ the preferences of Salop model, we assume the Chen-Riordan type preference for simplicity. See Chen and Riordan (2007, p. 903) for justification of these preferences.
} 
$\hat{x}_{23}\left(p_{2}, p_{3}\right)=\frac{5}{8}+\frac{v_{23}\left(q_{2}\right)-v_{23}\left(q_{3}\right)+p_{3}-p_{2}}{2 t}, \hat{x}_{30}\left(p_{3}, p_{0}\right)=\frac{7}{8}+\frac{v_{30}\left(q_{3}\right)-v_{30}\left(q_{0}\right)+p_{0}-p_{3}}{2 t}$.

Each firm simultaneously chooses its price $p_{i}$ to maximize its own profit. Define $\Delta_{i+1}=$ $v_{i+1}\left(q_{i}\right)-v_{i+1}\left(q_{i+1}\right)$. Assuming that an interior solution exists, we obtain the equilibrium prices as follows.

$$
\begin{array}{ll}
p_{0}^{*}=\frac{t}{4}+\frac{5\left(\Delta_{01}-\Delta_{30}\right)+\Delta_{12}-\Delta_{23}}{24}, & p_{1}^{*}=\frac{t}{4}+\frac{5\left(\Delta_{12}-\Delta_{01}\right)+\Delta_{23}-\Delta_{30}}{24}, \\
p_{2}^{*}=\frac{t}{4}+\frac{5\left(\Delta_{23}-\Delta_{12}\right)+\Delta_{30}-\Delta_{01}}{24}, & p_{3}^{*}=\frac{t}{4}+\frac{5\left(\Delta_{30}-\Delta_{23}\right)+\Delta_{01}-\Delta_{12}}{24} .
\end{array}
$$

After a few line computations, we obtain the equilibrium profit of firm $i$ as follows.

$$
\pi_{i}^{*}=\frac{\left(p_{i}^{*}\right)^{2}}{t}
$$

This leads us to the following proposition:

Proposition 3 (i) Firm 0 may have an incentive to transfer its quality-enhancing technology to a direct competitor. Formally,

$$
\frac{d \pi_{0}^{*}}{d q_{1}}>0 \Leftrightarrow \frac{v_{01}^{\prime}\left(q_{1}\right)}{v_{12}^{\prime}\left(q_{1}\right)}<\frac{1}{5} .
$$

(ii) Firm 0 has no incentive to transfer its quality-enhancing technology to an indirect competitor. Formally, $d \pi_{0}^{*} / d q_{2}<0$.

Because of its symmetry, note that this statement can be applied not only to firm 0 but also to other firms. The proposition makes two claims. The first claim is more illuminating, stating that a firm may have an incentive to transfer technology to its "direct competitors." The intuition behind part $(i)$ is similar to that of Proposition 1. When a technology transfer increases the valuation of type 12 more than that of type 01 , the increase in price can be so large that firm 1's demand from type 01 decreases. Since the prices of firms 2 and firm 3 decrease, firm 0's demand from type 30 decreases. When the condition for the proposition is satisfied, the technology transfer allows firm 0 to expand its total demand and increase its price and then get more profit. 
The second claim says that firms have no incentive for a technology transfer to an "indirect competitor." The technology transfer increases the demand of indirect competitor. The indirect competitor increase its price, whereas the direct competitors undercut their prices. This forces firm 0 to decrease its price, leading to a decreased profit.

Note that if the condition for claim (i) is satisfied, firm 2 does not have an incentive to transfer its technology to firm 1. Moreover, the condition for the technology transfer by firm 2 to firm 3 is independent of firm 1's quality. Thus, a technology transfer does not trigger another one.

\section{Concluding Remarks}

Our paper discusses competitor collaboration and shows some results contrary to the conventional wisdom that managers should protect their technologies from imitation. As discussed in our basic model, an advantaged firm may help its rival with quality-enhancing technology when there exist heterogeneous consumer groups who evaluate such quality enhancement differently. Although technology makes a rival firm more competitive in product' quality, it affects the rival's pricing strategy as well. The technology advantaged firm can benefit from such transfer by driving up the rival's price to obtain a larger market share. From this result, we further show that cost-reducing technology, which cuts down the technology recipient's price, should not be transferred.

We also discuss a circular model with four firms and resolve which rival would receive the technology. We show that a firm may benefit from transferring quality-enhancing technology to its direct competitor by driving up the recipient's price. A firm does not benefit from transferring its technology to an indirect competitor, because quality enhancement for the indirect competitor depresses the direct competitors' prices, and create a disadvantage for the technology advantaged firm.

Our model can distinguish the different effects of quality-enhancing and cost-reducing types of a technology transfer. Most existing models (e.g., Matsushima and Ogawa (2012) and Yoshida (2015)) can not distinguish these two types because both quality enhancement 
and cost reduction shift the technology recipient's best response curve outwards, which enlarges its output while intensifying competition. Our price-setting model can distinguish the effect of different types of technology transfer. The quality-enhancing type increases the technology recipient's price, whereas the cost-reducing one decreases it. We believe that the benefit of our model can be applied to other market structures (e.g., Bertrand model).

Welfare analysis is not involved in this paper because it is not always suitable with a Hotelling type demand. In our basic setting, enhanced quality increases consumers' willingness to pay, attracting more of them to the monopoly submarket and increasing the surplus of consumers there. However, from the standpoint of the whole market, asymmetries in consumer type, population, product quality, and production cost make analyzing the tradeoff between losses and gains in our model mathematically difficult to accomplish. Despite this, using a numerical simulation approach on the simplest case, wherein consumer's valuation of product quality takes a linear form, $v(q)=\theta q$, we are able to make an approximate prediction that quality-enhancing technology transfer enhances both social welfare and consumer surplus. However, the effects on each consumer group are different: the technology transfer enhances consumer surplus in the monopoly submarket but harms the surplus in the duopoly submarket. 


\section{References}

[1] Belleflamme, P. and M. Peitz, 2010, "Industrial Organization: Markets and Strategies," Cambridge: Cambridge University Press.

[2] Chen, Y. and M.H. Riordan, 2007, "Price and Variety in the Spokes Model," Economic Journal, 117(7), 897-921.

[3] Creane, A. and H. Konishi, 2009, "The Unilateral Incentives for Technology Transfers: Predation (and Deterrence) by Proxy," International Journal of Industrial Organization, 27(3), 379-389.

[4] Desai, P.S., 2001, "Quality Segmentation in Spatial Markets: When Does Cannibalization Affect Product Line Design?” Marketing Science, 20(3), 265-283.

[5] Ellison, G., 2005, “A Model of Add-on Pricing," Quarterly Journal of Economics, 120(2), 585-637.

[6] Ghosh, A. and H. Morita, 2012, "Knowledge Transfer and Partial Equity Ownership," UNSW Australian School of Business Research Paper, No. 2012 ECON 18, University of New South Wales.

[7] Gomes-Casseres, B. and J. Hagedoorn, 2006, "Do Alliances Promote Knowledge Flows?” Journal of Financial Economics, 80, 5-33.

[8] Hamel, G., 1991, “Competition for Competence in Inter-partner Learning within International Strategic Alliances," Strategic Management Journal, 12, 83-103.

[9] Harhoff, D., J. Henkel and E. von Hippel, 2003, "Profiting from Voluntary Information Spillovers: How Users Benefit by Freely Revealing Their Innovations," Research Policy, 32(10), 1753-1769. 
[10] Ishibashi, I. and N. Matsushima, 2009, “The Existence of Low-end Firms May Help High-end Firms," Marketing Science, 28(1), 136-147.

[11] Kamakura, W.A. and G.J. Russell, 1993, "Measuring Brand Value with Scanner Data," International Journal of Research in Marketing, 10, 9-21.

[12] Kogut, B., 1988, “Joint Ventures: Theoretical and Empirical Perspectives," Strategic Management Journal, 9, 319-332.

[13] Matsushima, N. and S. Ogawa, 2012, "Profit-enhancing Know-how Disclosure: A Strategic View," The Manchester School, 80(5), 560-579.

[14] Matsushima, N. and L. Zhao, 2015, "Strategic Dual Sourcing as a Driver for Free Revealing of Innovation,” ISER Discussion Paper No. 936, Institute of Social and Economic Research, Osaka University.

[15] Milliou, C. and E. Petrakis, 2012, "Vertical Integration, Knowledge Disclosure and Decreasing Rival's Cost," Economics Working Papers 12-13, Universidad Carlos III de Madrid, Departamento de Economía.

[16] Morita, H., S. Hayashi, K. Arai and M. Nishimura, 2010, "Kigyou no Teikei Bubuntekiketsugou ni Kansuru Kenkyu," (In Japanese) CR02-10, Competition Policy Research Center, Japan Fair Trade Commission.

[17] Mowery, D.C., 1983, “The Relationship between Intrafirm and Contractual Forms of Industrial Research in American Manufacturing, 1900-1940," Explorations in Economic History, 20, 351-374.

[18] Mowery, D.C., J.E. Oxley and B.S. Silverman, 1996, "Strategic Alliances and Interfirm Knowledge Transfer,’ Strategic Management Journal, 17, 77-91. 
[19] Pazgal, A., D. Soberman and R. Thomadsen, 2013, "Profit-increasing Consumer Exit," Marketing Science, 32(6), 998-1008.

[20] Qian, Y., 2014, "Brand Management and Strategies against Counterfeits," Journal of Economics and Management Strategy, 23(2), 317-343.

[21] Reggiani, C., 2014, "Spatial Price Discrimination in the Spokes Model," Journal of Economics and Management Strategy, 23, 628-649.

[22] Salop, S.C., 1979, “Monopolistic Competition with Outside Goods," Bell Journal of Economics, 10, 141-156.

[23] Shaked, A. and J. Sutton, 1982, "Relaxing Price Competition through Product Differentiation," Review of Economic Studies, 49, 3-14.

[24] Shi, H., Y. Liu and N.C. Petruzzi, 2013, "Consumer Heterogeneity, Product Quality, and Distribution Channels," Management Science, 59(5), 1162-1176.

[25] Tirole, J., 1988, “The Theory of Industrial Organization," Cambridge, MA: M.I.T. Press.

[26] Tyagi, R.K., 2004, “Technological Advances, Transaction Costs and Consumer Welfare,” Marketing Science, 23(3), 335-344.

[27] Varian, H., 1980, “A Model of Sales,” American Economic Review, 70, 651-659.

[28] Vickrey, W.S., 1964, "Microstatics," Harcourt, Brace and World, New York.

[29] Yoshida, S., 2015, “Multiproduct Competition in Vertically Related Industries,” ISER Discussion Paper No. 935, Institute of Social and Economic Research, Osaka University. 


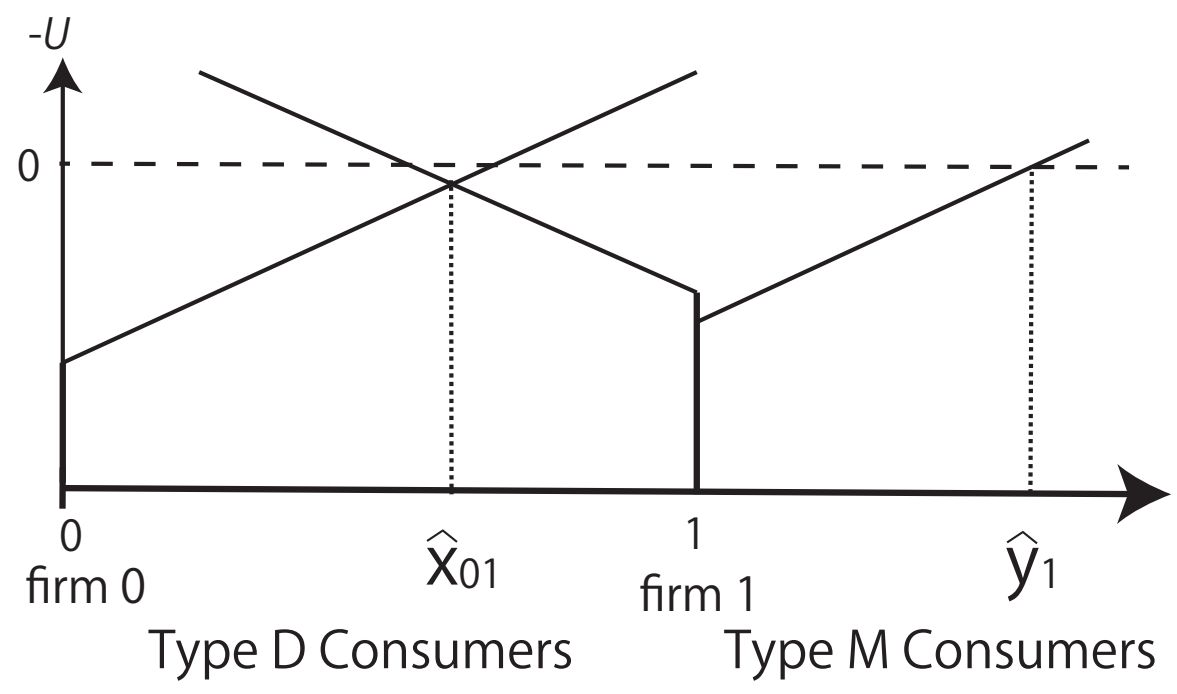

Figure 1: The market structure (linear)

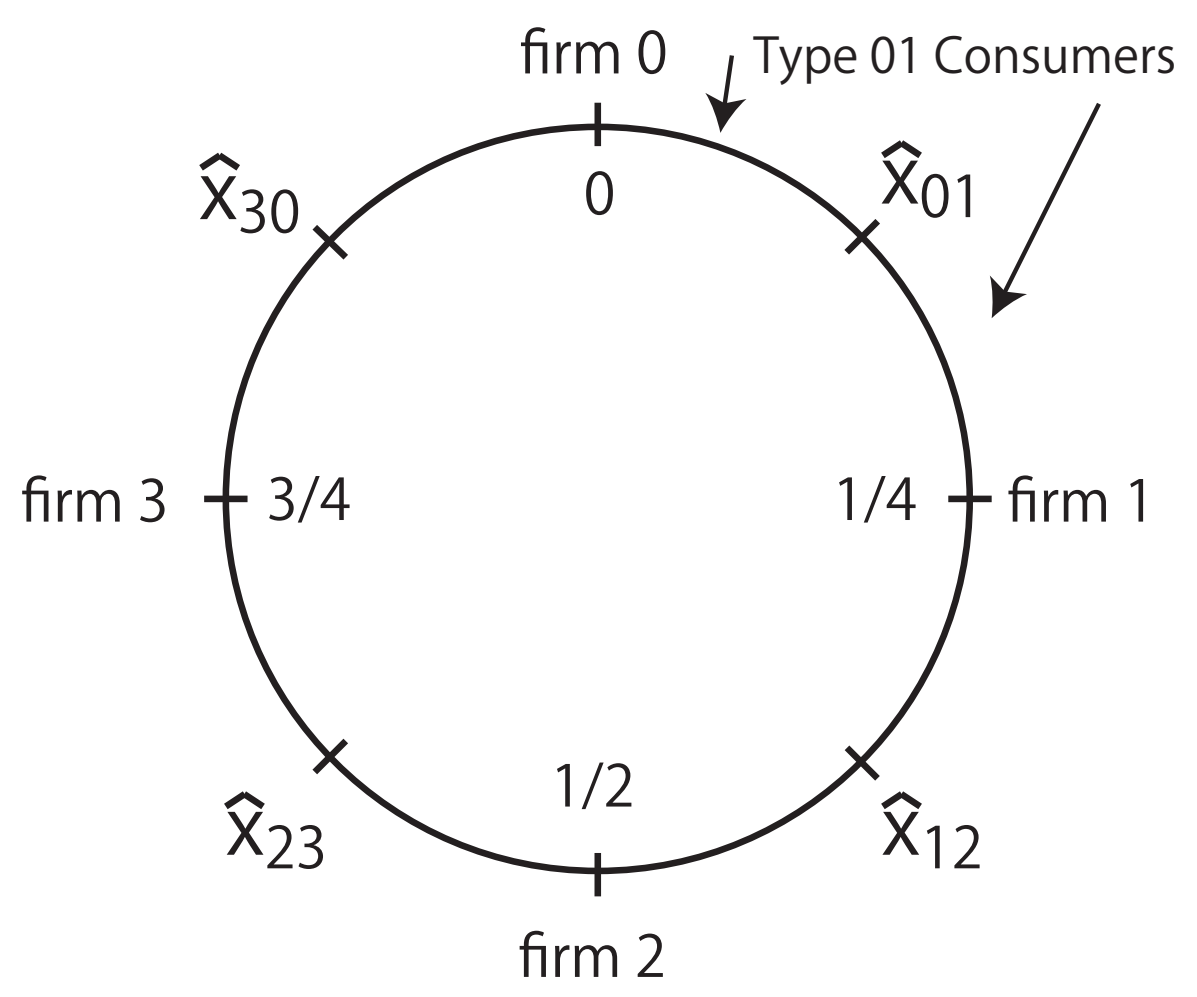

Figure 2: The market structure (circle) 